\title{
Enterprise Crowdfunding: Foundations, Applications, and Research Findings
}

\author{
Alexander Simons • Lena Franziska Kaiser • \\ Jan vom Brocke
}

Received: 15 March 2018/Accepted: 26 June 2018/Published online: 4 December 2018

(c) Springer Fachmedien Wiesbaden GmbH, ein Teil von Springer Nature 2018

Keywords Enterprise crowdfunding · Crowdfunding · Internal crowdfunding · Organizational crowdfunding · Corporate crowdfunding

\section{Introduction}

Crowdfunding has become the most important approach to online fundraising, with a global transaction value that is expected to annually grow by nearly 30 percent from 2018 to 2022 and total roughly US\$26 billion in 2022 (Statista 2018). Crowdfunding leverages the power of crowd work to collect money for financing startups and small businesses. While most traditional funding models collect large amounts of money from a small number of (often professional) investors, crowdfunding usually collects small amounts of money from a large number of (often casual) investors (e.g., Ahlers et al. 2015, p. 955; Belleflamme et al. 2014, p. 585; Hammon and Hippner 2012, p. 165). In only a few years, crowdfunding websites like Kickstarter and Indiegogo have helped people worldwide acquire funding for tens of thousands of projects and campaigns (Niemeyer et al. 2016, p. 2800). Kickstarter alone, launched less than 10 years ago, has collected pledges that totaled more than US\$4 billion (Kickstarter 2018).

Against this backdrop, it is not surprising that established companies have also developed an interest in crowdfunding. For example, Indiegogo recently launched a

Accepted after one revision by Prof. Weinhardt.

Dr. A. Simons $(\bowtie) \cdot$ L. F. Kaiser · Prof. Dr. J. vom Brocke Institute of Information Systems, University of Liechtenstein, Fürst-Franz-Josef-Strasse, 9490 Vaduz, Liechtenstein

e-mail: alexander.simons@uni.li program called "Indiegogo Enterprise", which several large companies, including Hasbro, Heineken, and Motorola, have joined (http://enterprise.indiegogo.com). In addition, companies like IBM and Siemens have implemented individual crowdfunding practices within their corporate realms (see, e.g., Hesse 2016; Muller et al. 2013). Since companies this big have ready access to traditional funding sources, why do they engage in crowdfunding? As this article explains, enterprise crowdfunding differs fundamentally from conventional crowdfunding, as it pursues targets other than fundraising.

Section 2 characterizes crowdfunding at a general level as a foundation for distinguishing between enterprise crowdfunding and conventional crowdfunding. Section 3 presents examples of how BMW, Bose, IBM, and Shock Top have used enterprise crowdfunding, and Sect. 4 reviews the extant research on enterprise crowdfunding. Section 5 synthesizes the findings from research and practice to conceptualize and characterize enterprise crowdfunding. Section 6 presents promising topics for future research, and Sect. 7 concludes the paper.

\section{Foundations}

The concept and practice of crowdfunding, a specific form of crowd work (Durward et al. 2016, p. 283), has been a topic of interest to researchers from several domains, including entrepreneurship and finance (Moritz and Block 2016, p. 45). A combination of the terms crowdsourcing and funding, crowdfunding's meaning seems intuitive, but the definition remains elusive because a variety of crowdfunding practices have emerged over the past few years (Mollick 2014, p. 2), including a wide variety of crowdfunding websites that serve considerably different purposes 
(Haas et al. 2014, p. 2). Based on what investors receive for their money on these websites, researchers have identified four basic crowdfunding practices (e.g., Burtch et al. 2014, p. 213): lending-based crowdfunding, which is used for private credits whose investors usually receive interest (see, e.g., Lin and Viswanathan 2016); equity-based crowdfunding, which is used for business startups whose investors usually receive revenue shares (see, e.g., Agrawal et al. 2014); reward-based crowdfunding, which is used for creative projects whose investors usually receive a nonmonetary reward, typically the product itself (see, e.g., Mollick 2014); and donation-based crowdfunding, which is used for charitable projects whose investors usually participate for altruistic reasons rather than tangible reward (see, e.g., Burtch et al. 2013).

This variety of crowdfunding practices has resulted in several definitions (Bouncken et al. 2015, p. 408), but most definitions have in common:

1. The primary purpose of fundraising (Cho and Kim 2017, p. 313), although crowdfunding also can serve other purposes, such as marketing (Mollick 2014, p. 3);

2. An open call for funding (Ahlers et al. 2015, p. 955), so crowdfunding reaches out to a large and undefined crowd (Kuppuswamy and Bayus 2018, p. 169);

3. Being Internet-based, so crowdfunding runs on intermediary platforms (Haas et al. 2014) or individual websites (Belleflamme et al. 2013).

In line with these characteristics, one of the most widely used crowdfunding definitions is that it "involves an open call, mostly through the Internet, for the provision of financial resources [...] to support initiatives for specific purposes" (Belleflamme et al. 2014, p. 588). However, as the following sections demonstrate, enterprise crowdfunding does not necessarily share these characteristics. We present examples of how companies have used enterprise crowdfunding and review available research findings, thereby providing a foundation on which to conceptualize and characterize enterprise crowdfunding and to assess its relevance to Information Systems research.

\section{Applications}

\subsection{Overview}

Enterprise crowdfunding is the most recent term in the crowdfunding arena, so even though several companies have used enterprise crowdfunding in the past few years, detailed information regarding drivers, objectives, solutions, and results is available for only a few cases. Against this backdrop, we present examples of enterprise crowdfunding from BMW, Bose, IBM, and Shock Top. While we identified the IBM and BMW cases based on a systematic literature review of some of the largest electronic databases, the Bose and Shock Top cases were identified based on a structured analysis of enterprise-crowdfunding campaigns on Indiegogo. The results of these analyses suggest that enterprise crowdfunding is usually used to create, collect, and assess ideas or to research and enter new markets - that is, to support a variety of innovation-related processes. The crowdfunding campaigns we selected illustrate the diversity of purposes that enterprise crowdfunding may serve, so they provide a good foundation on which to base a description and conceptualization of enterprise crowdfunding.

\subsection{The Case of BMW}

The German automobile-maker BMW was one of the earliest adopters of enterprise crowdfunding. As early as 2014, BMW launched the "Mobility Experience Challenge" on Startnext, the largest crowdfunding website that is presented in German. The campaign was open to all, including customers, developers, mobility experts, and even BMW's employees, who were asked to propose, describe, and evaluate innovative ideas for car apps, so the crowdfunding campaign was an idea contest, not a funding request (Jovanović et al. 2017, pp. 1 and 10). While the campaign resembled crowdsourcing, it leveraged the idea of crowdfunding to improve BMW's understanding of customers' needs and involve them in product development. Participants did not pledge their own money but received a virtual budget of $€ 100$, which they could "spend" on other participants' app ideas that were supposed to fall into one of three categories: "car", "travel", or "search and scout" (Boeriu 2014). BMW provided three sample ideas to illustrate what ideas should look like, and the idea-submission phase lasted 8 weeks, while the "funding" phase lasted 4 weeks (Jovanović et al. 2017, p. 5). BMW employee experts evaluated the ten app ideas that received most of the crowd's virtual funds, and three were awarded prize money totaling US\$2500 (Boeriu 2014). The three winners were then invited to present their ideas to BMW's App Decision Board.

By the time the campaign ended, 591 people had contributed by either proposing or evaluating app ideas; thirtyfive participants contributed 44 app ideas, and 602 votes were placed (Jovanović et al. 2017, p. 6). The experts did not select the three ideas that received the most funding but chose among the top ten apps that helped users learn about driving ("Drive Wise"), find assistance in an emergency ("Emergency-App"), and connect mobile devices with car- 
navigation systems ("RouteSync"). ${ }^{1}$ Bastian Bansemir, initiator of BMW's crowdfunding campaign, told us that the campaign helped BMW to improve their understanding of customers' needs and improve innovation development, concluding, "I think the initiative was a great success and made innovation development even more customer-centric. I highly appreciated the ideas shared by the community and really enjoyed its spirit".

\subsection{The Case of Bose}

Bose Corporation, a U.S.-based, privately held audio equipment maker, recently launched an Indiegogo campaign to fund development of earplugs that can help people sleep better by masking unwanted noises and replacing them with soothing sounds (Bose 2018). Bose's "Sleepbuds", which also incorporate an alarm that does not wake up the user's sleep partner (Carnoy 2017), differ from what Bose has produced in the past in that they do not play music and are much smaller than any of Bose's other wireless devices (Casserly 2017). However, with estimated sales of around US\$3.8 billion in 2017 (Bose 2017), Bose could easily have developed the product with its own money. So why did Bose engage in crowdfunding?

As Brian Mulcahey, Bose's Director of Emerging Business, explained, "We want[ed] to bring customers in earlier than we have traditionally done at Bose [to] validate the product vision" (as quoted in Casserly 2017). Therefore, the primary goal of Bose's crowdfunding campaign was not funding but prototyping. Bose used Indiegogo to find motivated testers and collect feedback on its prototype, so the Sleepbuds, whose estimated retail price is US $\$ 249$, were offered for only US\$150 (Casserly 2017). "We believe that testers who pay for the prototype are likely living with a severe 'noise in the bedroom' problem, they're going to use the prototype rigorously, and they'll provide more and better feedback" (as quoted in Ridden 2017). Bose was confident that Indiegogo's comment and survey functions would support this mission.

Bose's crowdfunding campaign was highly successful. The discounted US $\$ 150$ Sleepbuds quickly sold out, so Bose added several other reward tiers. In less than 3 months, all rewards were completely sold out, and the campaign had collected US $\$ 450,320$ in pledges from 2930 backers $-901 \%$ of Bose's funding goal of US $\$ 50,000 .^{2}$ The Sleepbuds have recently been shipped, so Bose has already received some feedback from its customer-testers

\footnotetext{
1 Visit www.startnext.com/pages/bmw\#contest for more information about BMW's Startnext campaign (accessed 05 Mar 2018).

${ }^{2}$ Visit www.indiegogo.com/projects/bose-noise-masking-sleepbudssold-out-sleep\#/ for more information about Bose's Indiegogo campaign (accessed 05 Mar 2018).
}

and decided to officially launch the product soon (Carnoy 2018). As Indiegogo (2018) commented on the campaign, "Who knew that there was a market for wireless earbuds that don't play music? Our community of 9.5 million early adopters did. They gave Bose a resounding green light for their new sleep technology by voting, not just with opinions, but with their wallets".

\subsection{The Case of IBM}

To foster internal innovation and collaboration, IBM launched probably the largest implementation of enterprise crowdfunding in 2012 through several campaigns, which helped IBM to collect employees' ideas and expertise (see Frick 2013). IBM's enterprise-crowdfunding platform (which was initially referred to as " $1 \times 5$ ") was first tested in two research departments, then adopted by a large IT department ("iFundIT"), and finally used to collect ideas from all IBM employees ("iFundIT3") (Feldmann and Gimpel 2016; Feldmann et al. 2014; Muller et al. 2013, 2014). All versions of IBM's enterprise-crowdfunding platform offered functionalities that were inspired by popular crowdfunding websites like Kickstarter and Indiegogo (Feldmann et al. 2014, p. 4; Muller et al. 2013, p. 504). Employees participated in these campaigns voluntarily using company money provided by senior management (Feldmann et al. 2014, p. 4). They lost any unspent money after the funding period expired ("use it or lose it"), and their projects could not collect more money than they targeted (Muller et al. 2013, p. 505).

The participation rates were high in IBM's enterprisecrowdfunding campaigns - participants submitted a variety of proposals that addressed diverse organizational and individual challenges - and, enterprise crowdfunding stimulated collaboration across departmental borders and organizational hierarchies (Muller et al. 2013, p. 510), so it helped IBM collect and evaluate innovative ideas from diverse employee groups (Feldmann et al. 2014, p. 4). The first campaign, which had a budget of only US $\$ 50,000$, still resulted in nineteen ideas that were funded out of thirtyfour proposed (Muller et al. 2013, pp. 505 f.). The IT campaign, which had a budget of US $\$ 150,000$, yielded ten projects that were funded out of fifty-five proposed (Feldmann et al. 2014, p. 4), and the corporate campaign, which had a budget of US\$4 million, resulted in forty-two ideas that were funded out of 204 proposed (Feldmann and Gimpel 2016, pp. 2 and 6). According to Power (2014), this expansion demonstrates "how social networking systems have begun to cross over from the consumer world to corporations to drive innovation. Not only does this approach give more control to employees, it results in innovative projects that are launched in a matter of weeks, not months". 


\subsection{The Case of Shock Top}

Shock Top, a California beer brand owned by AnheuserBusch, used Indiegogo to launch the "Shock the Drought" campaign, which supported projects that addressed the California drought and helped reduce water use (AnheuserBusch 2015). Shock Top's campaign differed from the other companies' crowdfunding campaigns because Shock Top played only a supporting role and did not seek funding for any of its own projects or products. From August 2015 to January 2016, Shock Top supported three projects: Drop-A-Brick 2.0, which promoted use of a rubber brick that can be placed into toilet tanks to save water, with US\$100,000; EvaDrop, a shower head with sensors and a timer that can significantly limit water use, with US\$62,000; and Droppler, a smart water gauge that provides data on water usage, with US\$50,000, plus marketing support (Brown et al. 2017, p. 191). Shock Top's financial support helped reduce these products' retail prices, and Shock Top also donated some of these products to waterconservation organizations in California (Hessekiel 2015). Jake Kirsch, Vice President of Shock Top, said, "Working together, we can Shock the Drought by sharing great ideas, pledging support and funding new inventions, and we're excited to lead this charge" (Anheuser-Busch 2015). ${ }^{3}$

The official objective of the Shock the Drought campaign was to "to identify, fund and distribute water-saving innovations that have the potential to make a real impact on reducing water usage in the state" (Anheuser-Busch 2015), but it also strengthened Shock Top's brand identity (Brown et al. 2017, p. 192). The preservation of natural resources, particularly water, is of major concern to millennials, who are Shock Top's core customers, and one out of every four Shock Top brews is sold in California (Hessekiel 2015). Accordingly, Shock Top had good reason to show it was committed to California's environment, so it used enterprise crowdfunding to strengthen its brand's identity by building it around a good cause (Brown et al. 2017, p. 191).

\section{Research Findings}

Despite these examples from practice, which suggest that companies increasingly use enterprise crowdfunding, academic research on enterprise crowdfunding is still in its infancy. Most of the few studies that have been published have focused on the IBM case, which has been studied from a social-networking perspective and from a decisionmaking perspective.

\footnotetext{
3 Visit www.indiegogo.com/campaign_collections/shock-thedrought for more information about Shock Top's Indiegogo campaign (accessed 05 Mar 2018).
}

Muller and colleagues studied the IBM case from a social-networking perspective and suggested that enterprise crowdfunding can have significantly higher participation rates than other social-media campaigns, as it helps overcome both hierarchical and departmental barriers and allows employees to initiate organizational change (Muller et al. 2013, pp. 506 ff.); that geographical similarities, work-group similarities, and company-division similarities among project creators and supporters are associated with higher investments, while prior relationships between them play only a minor role (Muller et al. 2014, pp. $782 \mathrm{ff}$.); that joint projects from several creators have higher success rates than projects with fewer or single creators (Muller et al. 2016, pp. $1251 \mathrm{ff}$.); and that people with larger social networks take more prominent roles in enterprise crowdfunding, which can also help them extend their social networks (Muller et al. 2018, pp. 24 f.).

The studies on the IBM case that have taken a decisionmaking perspective have suggested that employees tend to make decisions about whether to fund a project idea quickly (Feldmann et al. 2014, pp. 5ff.). The presentation and design of project ideas have also been studied from the perspective of decision-making. For example, Feldmann and Gimpel (2016, pp. 7 f.) found that idea elaboration positively affects funding success, while self-containment negatively affects funding success, and that measures of idea quality - such as novelty, relevance, and feasibility play a surprisingly small role. The design of IBM's internal crowdfunding platforms has also been studied, and design principles have been proposed (e.g., to create guidelines for idea description or to implement separate rounds of crowdfunding based on project categories) (Feldmann et al. 2014, p. 8).

Another internal enterprise-crowdfunding campaign has been studied at Siemens, a German-based manufacturing company. Siemens launched its own Intranet website, "Quickstarter", in 2015 and has held several crowdfunding contests since then (see Hesse 2016). The Quickstarter contests resembled IBM's crowdfunding campaigns, although Siemens separated theirs into two phases: an ideation phase during which employees submitted ideas, and an investment phase during which employees spent company money on these ideas (Schweisfurth et al. 2017b, p. 7). The contests sought to support innovation by collecting ideas from employees, so they also helped foster inter-departmental discussions among employees. The Siemens case supports some of the findings from the IBM case; for example, it suggests that enterprise crowdfunding may suffer from hierarchical similarity biases (i.e., employees' idea evaluations tend to be more favorable if they are hierarchically similar to the idea creator) (Schweisfurth et al. 2017b, p. 1), especially for highly innovative and novel ideas (Schweisfurth et al. 2017a). 
While researchers have given some attention to crowdfunding that has used corporations' intranets, enterprisecrowdfunding campaigns that have used the public Internet have rarely been studied. Apart from the IBM studies, most researchers have approached enterprise crowdfunding from a conceptual perspective. For example, enterprise crowdfunding has been conceptualized from a prediction-market perspective (Feldmann et al. 2013), a marketing perspective (Brown et al. 2017), and a process perspective (Gómez et al. 2016). However, only a few researchers have used empirical data to study Internet-based enterprise-crowdfunding campaigns. An exception is the BMW case, which was used to identify design elements for online crowdfunding contests (e.g., regarding time frames, target groups, budgets, and rewards) (Jovanović et al. 2017, pp. 6 ff.). As Brown et al. (2017, pp. 193 f.) concluded, established companies' increasing engagement in online crowdfunding may have a profound impact on the crowdfunding industry, but this impact and other urgent questions have yet to be studied. The following sections provide a foundation for future research by offering a conceptualization of enterprise crowdfunding and an outlook on potentially useful research topics.

\section{Synthesis}

The available applications and extant research demonstrate that crowdfunding is useful not only for startups and small businesses but also for established companies. They also show that companies have used enterprise crowdfunding in diverse ways, which makes it difficult to define enterprise crowdfunding. Still, the synthesis of results from research and practice provides a foundation on which to conceptualize enterprise crowdfunding at a general level and separate it from conventional crowdfunding. At the most basic level, enterprise crowdfunding takes either of two approaches: internal or external.

Internal crowdfunding happens within corporations, so it is not open to the public. For example, IBM, Siemens, and companies like Daimler (see Lehrbass 2017) have created their own internal crowdfunding platforms. In internal crowdfunding, employees propose and evaluate projects, so part of the objective is to involve and engage them in innovation management and to foster collaboration among them (see, e.g., Feldmann et al. 2014; Muller et al. 2013). Employees spend corporate money to fund the project ideas and engage in enterprise crowdfunding because it gives them an opportunity to address organizational and individual challenges, initiate organizational change, and have a say in project management (Muller et al. 2013, p. 511). The budgets the corporations allocate to these projects are shared resources that employees spend on ideas that they believe provide the best benefits to themselves or their organization (Muller et al. 2014, p. 779), so internal crowdfunding can help to overcome corporate borders and hierarchies and may foster collaboration across departments and among diverse groups of employees (Muller et al. 2013, p. 503). As it leverages collective intelligence, internal crowdfunding can also help companies manage their increasingly large portfolios of ideas and accelerate the approval process for novel projects (Feldmann et al. 2014, p. 2).

While the earliest corporate crowdfunding campaigns were internal, external crowdfunding has also gained momentum, especially on Indiegogo. External crowdfunding involves an open call to the public. External crowdfunding projects tend to be much more diverse than internal crowdfunding projects are. For example, the Bose case and cases like FirstBuild (Kapoor et al. 2017, p. 3) demonstrate that companies increasingly use crowdfunding for prototyping. As Joel Hughes, Indiegogo's Director of UK and Europe, explained, "recently, established businesses have been using crowdfunding platforms before they prepare for mass-manufacturing of their products [, n] ot because they need the funds, but because the market validation and opportunity to connect with customers through crowdfunding is incredibly useful" (as quoted in Knowles 2017). However, companies also use enterprise crowdfunding for other reasons. For example, BMW used a crowdfunding website for an idea contest, which was similar to how companies like Hasbro have engaged in enterprise crowdfunding (Key 2017). As these companies did not have a finished product to be crowdfunded, they used the crowd to collect and evaluate innovative product ideas (Brown et al. 2017, pp. 192 ff.). In addition, as the Shock Top case demonstrates, some companies have also used crowdfunding to strengthen their brand identities. Camden Town, a London beer brewery, even used crowdfunding to raise funds to expand its production capacity and export beer outside the U.K. (Brown et al. 2017, p. 191).

Clearly, the reasons of why companies engage in enterprise crowdfunding differ, and an enterprise-crowdfunding campaign usually pursues diverse objectives. For example, as Jovanović et al. (2017, p. 1) explained, BMW's idea contest had three major strategic objectives: marketing, evaluation, and financing. Brown et al. (2017, p. 192) analyzed established companies' crowdfunding campaigns on the Internet and concluded that they all pursued several objectives, many of which were similar, even though they all had unique primary targets that drove the campaigns. Therefore, internal and external enterprise crowdfunding can also have similar objectives. For example, the BMW case was external but had objectives that resembled those of IBM's and Siemens' internal 
campaigns. Still, the common denominator in all these cases is that the crowdfunding campaigns were promoted by established companies, not startups or small businesses, and that fundraising usually was not the primary goal but was used as a way to pursue other objectives (e.g., idea creation, marketing, branding, and/or prototyping).

As these objectives were diverse, the reasons of why participants engaged in enterprise crowdfunding also differed. While BMW offered monetary rewards, IBM and Siemens employees had an intrinsic motivation to engage in crowdfunding, and Bose reached out to potential customers of its earbuds. As a result, the process of crowdfunding also varied. In the Bose case, for example, backers pledged their own money to get early access to product prototypes, just like conventional crowdfunding campaigns that use rewards, while BMW collected virtual money and rewarded the best ideas, and IBM employees spent company money to evaluate ideas that they believed would benefit the company.

These findings provide a foundation on which to separate enterprise crowdfunding from conventional crowdfunding. We used a review of the extant literature to identify three characteristics of conventional crowdfunding: (1) its primary objective is fundraising; (2) it involves an open call; and (3) it is typically online, using either intermediary platforms or individual websites. However, the synthesis of results from research and practice suggests that enterprise crowdfunding does not necessarily share these characteristics: (1) enterprise crowdfunding does not usually seek funds; (2) only external crowdfunding involves an open call, while internal crowdfunding is limited to a company's employees; and (3) only external crowdfunding is Internet-based, as internal crowdfunding uses Intranet platforms. Based on these conclusions, we characterize enterprise crowdfunding as follows:

Enterprise crowdfunding is used by established companies and is not typically used for fundraising but for other reasons, which determine how it is implemented. Internal enterprise crowdfunding is primarily used to foster innovation and collaboration among employees, who propose and evaluate project ideas on Intranet platforms by allocating company money. External enterprise crowdfunding is often used to collect ideas from people outside a company, who propose and evaluate ideas on Internet platforms, but it can also serve other purposes, including prototyping and branding.

As enterprise crowdfunding is an emerging phenomenon, and because some companies have used it for other purposes, including fundraising, this definition is not meant to be exhaustive and may require adaptation. Still, it may help researchers to conceptualize enterprise crowdfunding in future research studies.

\section{Future Research}

Several useful topics may guide future research. First, future research should focus on further conceptualizing enterprise crowdfunding, both from an internal and external perspective. As explained, the term crowdfunding is a combination of the terms crowdsourcing and funding, and while conventional crowdfunding leverages the idea of crowdsourcing for fundraising (see Mollick 2014, p. 2), it is the opposite with internal crowdfunding, which leverages the idea of fundraising for crowdsourcing (see Malhotra et al. 2017, p. 73). Therefore, internal crowdfunding has much in common with several well-known concepts, including participatory budgeting (Niemeyer et al. 2016), idea-evaluation communities, intra-organizational idea markets, and bottom-up idea-evaluation systems (Schweisfurth et al. 2017b, p. 3), from which future research should distinguish internal crowdfunding. As for external crowdfunding, future applications are likely to extend its scope as described in this article, so future research is challenged to develop a conceptualization of external crowdfunding that considers the diversity of purposes that Internet-based crowdfunding campaigns may serve. In doing so, researchers should also take into account recent technological trends, particularly blockchain (see Mendling et al. 2018), as companies like Chainium have started to build crowdfunding platforms based on blockchain technology with which private and public businesses can sell equity (Smith 2018). As blockchain may provide a more secure, efficient, and low-cost crowdfunding solution than intermediaries (Zhu and Zhou 2016, p. 1), future research is challenged to evaluate the usefulness of blockchain technology in crowdfunding contexts.

Second, internal crowdfunding is particularly interesting for design-oriented research. While research on conventional crowdfunding has studied the design of crowdfunding projects in pursuit of funding targets, the design of crowdfunding websites has been taken largely for granted. That companies typically develop and use individual platforms in internal crowdfunding offers opportunities for design-science researchers. Research on the IBM case has delivered first design principles (Feldmann et al. 2014, pp. $7 \mathrm{f}$.), but researchers are still challenged to study other companies' crowdfunding campaigns to theorize about the design and use of internal crowdfunding platforms on a more general level. In fact, several calls for further research remain unanswered, even though research on internal crowdfunding has considerable potential from the 
perspective of data analysis, as new data sources, such as $\log$ files (e.g., Feldmann et al. 2014, p. 3), can be analyzed.

Such data sources may facilitate a holistic exploration of crowdfunding from a decision-making perspective. The reasons that employees engage in enterprise crowdfunding differ significantly from those of conventional crowdfunding (Muller et al. 2013, pp. 507 f.), so employees may also make their decisions differently than the public does. For example, Feldmann et al. $(2014$, p. 3) argued that participants in enterprise crowdfunding may be prone to heuristic system-1 thinking, which is fast, effortless, and often unconscious, rather than slow, controlled, and reflective system-2 thinking (Evans 2008, p. 257). While research on conventional crowdfunding has also found that backers may be prone to system-1 thinking, but only under certain conditions (e.g., Simons et al. 2017, p. 4346), future research should explore to what extent employees, who engage in enterprise crowdfunding by pledging corporate money, make use of heuristics. Such research could be useful to those who design internal crowdfunding in particular because it may suffer from hierarchical similarity bias (Schweisfurth et al. 2017a, b). For example, employees may tend to support ideas that are proposed by colleagues in their own divisions, especially when they are part of a small subdivision (Reitzig and Sorenson 2013, pp. 790 ff.). From a design perspective, knowledge about cognitive heuristics and biases can be used to alter employees' behavior in a beneficial way (e.g., to promote sustainable, charitable, or social projects), a process known as digital nudging (Weinmann et al. 2016).

Future research should also observe the impact that established companies' engagement in crowdfunding has on crowdfunding communities and the crowdfunding industry as such (Brown et al. 2017, pp. 193 f.). People engage in crowdfunding for various reasons: for financial returns, to collect rewards like products, for altruism, for fun, or because they identify with projects and project teams and want to support small-business owners' innovative ideas (Bretschneider et al. 2014, pp. 4 ff.). It will be interesting to see to what extent regular backers also identify with established companies and how crowdfunding communities will perceive and accept established companies' engagement in crowdfunding. In addition, this engagement may make fundraising more difficult for startups and small businesses that have much smaller marketing budgets and professional networks (Brown et al. 2017, p. 194). Accordingly, future research should explore backers' motivation to support established companies' crowdfunding projects and identify the characteristics of the companies, projects, and websites that have used enterprise crowdfunding successfully. In addition, several other questions deserve researchers' attention. For example, fraud is a major problem on several crowdfunding websites, so trust has become a major barrier to online fundraising (Kang et al. 2016, p. 1801). Such may not be the case with established companies' projects, as they tend to have credible reputations that help them compete with small and largely unknown businesses. As Brown et al. (2017, p. 193) proposed, future research should also explore reputational risks that are associated with companies' engagement in crowdfunding, as projects could fail to reach their funding targets, exceed their delivery dates, or result in products that do not meet backers' expectations, among other risks. While other questions are likely to emerge as established companies increasingly make use of crowdfunding, it is safe to say that enterprise crowdfunding has much to offer for researchers from several domains, including Information Systems.

\section{Conclusions}

While crowdfunding on the Internet is used increasingly to finance startups and small businesses, many established companies have also realized that crowdfunding has much to offer. However, enterprise crowdfunding differs fundamentally from conventional crowdfunding practices. We presented examples of how companies have used enterprise crowdfunding and reviewed available research findings to clarify the meaning, functionality, and scope of enterprise crowdfunding. The synthesis of results from research and practice suggests that established companies do not use enterprise crowdfunding for fundraising, although there are exceptions, but for several other purposes, including idea creation, prototyping, branding, and collaboration. While enterprise crowdfunding has received little attention from academia, it offers research opportunities from both a design-oriented perspective and a behavioral perspective. Therefore, this article may guide future research on enterprise crowdfunding in the Information Systems domain.

\section{References}

Agrawal A, Catalini C, Goldfarb A (2014) Some simple economics of crowdfunding. Innov Policy Econ 14(1):63-97

Ahlers GKC, Cumming D, Günther C, Schweizer D (2015) Signaling in equity crowdfunding. Entrep Theory Pract 39(4):955-980

Anheuser-Busch (2015) Shock Top and Indiegogo team up to shock the California drought by dropping bricks in toilets (and that's just the beginning). http://www.anheuser-busch.com/newsroom/ 2015/08/shockthedrought.html. Accessed 06 June 2018

Belleflamme P, Lambert T, Schwienbacher A (2013) Individual crowdfunding practices. Venture Cap 15(4):313-333

Belleflamme P, Lambert T, Schwienbacher A (2014) Crowdfunding: tapping the right crowd. J Bus Ventur 29(5):585-609 
Boeriu H (2014) BMW and Startnext challenge international fans, innovators and developers for car app ideas. BMW Blog. http:// www.bmwblog.com/2014/08/31/bmw-startnext-challenge-inter national-fans-innovators-developers-car-app-ideas/. Accessed 06 June 2018

Bose (2017) Bose sustainability report. https://assets.bose.com/ content/dam/Bose_DAM/Web/consumer_electronics/global/con tent_pages/corporate/about_us/sustainability/pdf/Bose_2017_ Sustainability_Report.pdf. Accessed 06 June 2018

Bose (2018) Bose noise-masking Sleepbuds. https://www.bose.com/ en_us/products/headphones/noise_masking_sleepbuds/noisemasking-sleepbuds.html. Accessed 05 June 2018

Bouncken RB, Komorek M, Kraus S (2015) Crowdfunding: the current state of research. Int Bus Econ Res J 14(3):407-416

Bretschneider U, Knaub K, Wieck E (2014) Motivations for crowdfunding: what drives the crowd to invest in start-ups? In: Proceedings of the 22nd European conference on information systems, Tel Aviv, Israel

Brown TE, Boon E, Pitt LF (2017) Seeking funding in order to sell: crowdfunding as a marketing tool. Bus Horiz 60(2):189-195

Burtch G, Ghose A, Wattal S (2013) An empirical examination of the antecedents and consequences of contribution patterns in crowdfunded markets. Inf Syst Res 24(3):499-519

Burtch G, Di Benedetto CA, Mudambi SM (2014) Leveraging information systems for enhanced product innovation. In: Martínez-López FJ (ed) Handbook of strategic e-business management. Springer, Heidelberg, pp 211-216

Carnoy D (2017) Bose's new noise-masking Sleepbuds may change your life. CNET. https://www.cnet.com/news/boses-new-noisemasking-sleep-buds-may-change-your-life/. Accessed 05 Mar 2018

Carnoy D (2018) Bose noise-masking Sleepbuds will be officially introduced June 20. CNET. https://www.cnet.com/news/bosesleepbuds-will-be-officially-introduced-june-20/. Accessed 04 June 2018

Casserly I (2017) Bose is crowdfunding noise-cancelling earbuds that can help you sleep. TNW. https://thenextweb.com/insider/2017/ 11/15/bose-is-crowdfunding-noise-cancelling-earbuds-that-canhelp-you-sleep/. Accessed 05 Mar 2018

Cho M, Kim G (2017) A cross-cultural comparative analysis of crowdfunding projects in the United States and South Korea. Comput Hum Behav 72:312-320

Durward D, Blohm I, Leimeister JM (2016) Crowd work. Bus Inf Syst Eng 58(4):281-286

Evans JSBT (2008) Dual-processing accounts of reasoning, judgment, and social cognition. Annu Rev Psychol 59:255-278

Feldmann N, Gimpel H (2016) Financing projects through enterprise crowdfunding: understanding the impact of proposal characteristics on funding success. In: Proceedings of the 24th European conference on information systems, Istanbul, Turkey

Feldmann N, Gimpel H, Kohler M, Weinhardt C (2013) Using crowd funding for idea assessment inside organizations: lessons learned from a market engineering perspective. In: Proceedings of the 2013 IEEE 3rd international conference on cloud and green computing, Karlsruhe, Germany, pp 525-530

Feldmann N, Gimpel H, Muller M, Geyer W (2014) Idea assessment via enterprise crowdfunding: an empirical analysis of decisionmaking styles. In: Proceedings of the 22nd European conference on information systems, Tel Aviv, Israel

Frick W (2013) Can internal crowdfunding help companies surface their best ideas? Harvard Bus Rev. https://hbr.org/2013/09/caninternal-crowdfunding-help-companies-surface-their-best-ideas. Accessed 05 Mar 2018

Gómez JM, Sandau A, Sevimli K, Schmitt C, Halberstadt J (2016) Proof of concept: enterprise crowdfunding. In: Proceedings of the 9th international conference on information resources management, Cape Town, South Africa

Haas P, Blohm I, Leimeister JM (2014) An empirical taxonomy of crowdfunding intermediaries. In: Proceedings of the 35th international conference on information systems, Auckland, New Zealand

Hammon L, Hippner H (2012) Crowdsourcing. Bus Inf Syst Eng 4(3):163-166

Hesse J (2016) Open innovation: fertile ground for innovations. Siemens. https://www.siemens.com/innovation/en/home/pic tures-of-the-future/research-and-management/innovations-openinnovation.html. Accessed 05 Mar 2018

Hessekiel D (2015) Crowdfunding, water conservation \& beer: how cool can you get? Forbes. http://www.forbes.com/sites/davidhes sekiel/2015/09/01/crowdfunding-water-conservation-beer-howcool-can-you-get/\#ec8663156d9f. Accessed 05 Mar 2018

Indiegogo (2018) Innovation validation for large enterprises. http:// enterprise.indiegogo.com/. Accessed 05 Mar 2018

Jovanović T, Bansemir B, Kirchner M, Voigt K-I (2017) The crowdfunding idea contest of BMW. In: Proceedings of the 26th international association for management of technology conference, Vienna, Austria

Kang M, Gao Y, Wang T, Zheng H (2016) Understanding the determinants of funders' investment intentions on crowdfunding platforms: A trust-based perspective. Ind Manag Data Syst 116(8):1800-1819

Kapoor B, Nolan K, Venkatakrishnan N (2017) How GE appliances built an innovation lab to rapidly prototype products. Harvard Bus Rev. https://hbr.org/2017/07/how-ge-built-an-innovationlab-to-rapidly-prototype-appliances. Accessed 05 Mar 2018

Key S (2017) Hasbro-Indiegogo partnership celebrates the benefits of open innovation. Entrep Eur. https://www.entrepreneur.com/ article/292151. Accessed 04 June 2018

Kickstarter (2018) Stats. https://www.kickstarter.com/help/stat s?lang=en. Accessed 01 Dec 2018

Knowles K (2017) Why Bose is crowdfunding its new sleep earbuds. The Memo. https://www.thememo.com/2017/11/15/bose-indie gogo-bose-sleep-earbud-crowdfunding-big-business-finance-fin tech/. Accessed 05 Mar 2018

Kuppuswamy V, Bayus BL (2018) Crowdfunding creative ideas: the dynamics of project backers. In: Cumming D, Hornuf L (eds) The economics of crowdfunding: startups, portals and investor behavior. Palgrave Macmillan, Cham, pp 151-182

Lehrbass L (2017) Supplier innovation \& internal crowdfunding. Innosabi. http://innosabi.com/en/2017/11/06/supplier-innova tion-internal-crowdfunding/. Accessed 05 Mar 2018

Lin M, Viswanathan S (2016) Home bias in online investments: an empirical study of an online crowdfunding market. Manag Sci 62(5):1393-1414

Malhotra A, Majchrzak A, Kesebi L, Looram S (2017) Developing innovative solutions through internal crowdsourcing. MIT Sloan Manag Rev 58(4):73-79

Mendling J, Weber I, van der Aalst W, vom Brocke J, Cabanillas C et al (2018) Blockchains for business process management: challenges and opportunities. ACM Trans Manag Inf Syst 9(1):1-16

Mollick E (2014) The dynamics of crowdfunding: an exploratory study. J Bus Venturing 29(1):1-16

Moritz A, Block JH (2016) Crowdfunding: a literature review and research directions. In: Brüntje D, Gajda O (eds) Crowdfunding in Europe: state of the art in theory and practice. Springer, Heidelberg, pp 25-53

Muller M, Geyer W, Soule T, Daniels S, Cheng L-T (2013) Crowdfunding inside the enterprise: employee-initiatives for innovation and collaboration. In: Proceedings of the ACM 
SIGCHI conference on human factors in computing systems, Paris, France, pp 503-512

Muller M, Geyer W, Soule T, Wafer J (2014) Geographical and organizational commonalities in enterprise crowdfunding. In: Proceedings of the 17th ACM conference on computer-supported cooperative work and social computing, Baltimore, MD, USA, pp 778-789

Muller M, Keough M, Wafer J, Geyer W, Saez AA, Leip D, Viktorov C (2016) Social ties in organizational crowdfunding: benefits of team-authored proposals. In: Proceedings of the 19th ACM conference on computer-supported cooperative work and social computing, San Francisco, CA, USA, pp 1246-1259

Muller M, Mitra T, Geyer W (2018) Growth in social network connectedness among different roles in organizational crowdfunding. In: Proceedings of the ACM international conference on supporting group work, Sanibel Island, FL, USA, pp 22-26

Niemeyer C, Wagenknecht T, Teubner T, Weinhardt C (2016) Participatory crowdfunding: an approach towards engaging employees and citizens in institutional budgeting decisions. In: Proceedings of the 49th Hawaii international conference on system sciences, Koloa, HI, USA, pp 2800-2808

Power B (2014) Improving decision-making with help from the crowd. Harvard Bus Rev. https://hbr.org/2014/04/improve-decision-mak ing-with-help-from-the-crowd. Accessed 05 Mar 2018

Reitzig M, Sorenson O (2013) Biases in the selection stage of bottomup strategy formulation. Strateg Manag J 34(7):782-799

Ridden P (2017) Bose tries crowdsourcing to develop sleep improving earbuds. New Atlas. https://newatlas.com/bose-sleepbuds/52165/ . Accessed 04 June 2018
Schweisfurth TG, Zaggl MA, Schöttl CP (2017a) Does similarity between evaluator and creator affect the evaluation of ideas? In: Academy of management proceedings, vol 2017, no 1

Schweisfurth TG, Zaggl MA, Schöttl CP, Raasch C (2017b) Hierarchical similarity biases in idea evaluation: a study in enterprise crowdfunding. Kiel working paper 2095. http://hdl. handle.net/10419/172003. Accessed 06 June 2018

Simons A, Weinmann M, Tietz M, vom Brocke J (2017) Which reward should I choose? Preliminary evidence for the middleoption bias in reward-based crowdfunding. In: Proceedings of the 50th Hawaii international conference on system sciences, Waikoloa Village, HI, USA, pp 4344-4353

Smith O (2018) Why blockchain is booming in Liechtenstein, the sixth smallest country in the world. Forbes. https://www.forbes. com/sites/oliversmith/2018/03/07/why-blockchain-is-boomingin-liechtenstein-the-sixth-smallest-country-in-the-world/ \#75e809da3564. Accessed 12 Mar 2018

Statista (2018) Crowdfunding. https://www.statista.com/outlook/335/ 100/crowdfunding/worldwide\#. Accessed 05 Mar 2018

Weinmann M, Schneider C, vom Brocke J (2016) Digital nudging. Bus Inf Syst Eng 58(6):433-436

Zhu H, Zhou ZZ (2016) Analysis and outlook of applications of blockchain technology to equity crowdfunding in China. Financ Innov 2(29):1-11 